\title{
Growth dynamics of tomato fruits as a main indicator of a phytomonitor
}

\author{
Yuri Sleptsov ${ }^{1, *}$, Varvara Bogdanova ${ }^{2}$, and Mikhail Vorobyev ${ }^{2}$ \\ ${ }^{1}$ National University of Life and Environmental Sciences of Ukraine, 03041 Kyiv, Ukraine \\ ${ }^{2}$ Russian State Agrarian University-Timiryazev Agricultural Academy, 127550 Moscow, Russia
}

\begin{abstract}
The study of the growth dynamics of tomato fruits in greenhouses using a phytomonitor, in particular, a fruit growth sensor, shows indicators that are invisible to the human eye. Their dynamics during the day and throughout the entire period of fetal development, starting from a size of $2.7 \mathrm{~cm}$ to removable maturity and redness in a graphical form, allows you to quickly identify a slowdown in growth, quickly find a limiting factor and reveal the influence on the growth rate of factors such as brush rationing and cleaning other fruits in it. It must be said that the use of a phytomonitor in practice requires high qualifications of an agronomist. And if the farm does not have a sufficiently high level of agricultural technology or the staff does not know how to use the indicators of sensors, there is no point in looking for a limiting factor. For this reason, in the greenhouses of Corporation "Kombinat Teplichny" (Kiev region, the village of Kalinovka), after several years of use, they abandoned the phytomonitor, which did not recoup the funds invested in it. For Ukraine, it remains exotic, therefore, the article contains an extended description of the phytomonitor.
\end{abstract}

\section{Introduction}

The use of phytomonitoring with a sensor system has become a widespread system for diagnosing the functional state of a plant. Its main advantage, which has already been appreciated by experts, is the registration of the slightest deviation from the optimal parameters. The human eye is not able to notice, for example, fluctuations in micrometers $(\mu \mathrm{m})$ of the stem diameter in case of water deficit, changes in xylem sap flow, or an increase in leaf temperature by several degrees. When the signs of deviation from the optimal parameters will be noticeable externally, up to $15-20 \%$ of the crop will already be lost. This is the essence of the phytomonitor, which presents a sensor for measuring leaf temperature, a sensor for measuring the rate of xylem sap flow, a sensor for measuring stem diameter and a sensor for fruit growth. Of all the sensors, the last one is by far the most important, since the end result of all measurements is the measures taken, which are expressed in the growth rate of the fruits of any crop.

Daily slowdown or cessation of growth in the human eye is invisible, even with a systematic examination of one plant, while the fruit growth sensor quickly registers this

* Corresponding author: helicopter09@ukr.net 
parameter and allows you to quickly find the cause based on other indicators. For example, a slowdown in friut growth after watering means overflow, a sharp increase in speed means a lack of moisture (a signal to increase the irrigation regime). If the leaf temperature rises with a decrease in the stem diameter, this is again a lack of water in the plant, a slowdown in fruit growth with an optimal combination of other factors - a lack of CO2. Of course, fruit growth depends on a set of interrelated other factors. All this made it possible to establish functional relationships between plant parameters. However, the use of a phytomonitor requires a high level of qualification of an agronomist. In addition, there are very few recommendations for the practical use of sensors. Therefore, such works are relevant, illustrating practical results, without being overloaded with formulas, which was the topic of the work. There is a wide variety of phytomonitoring sensors available from different manufacturers. But it is based on an LVDT sensor.

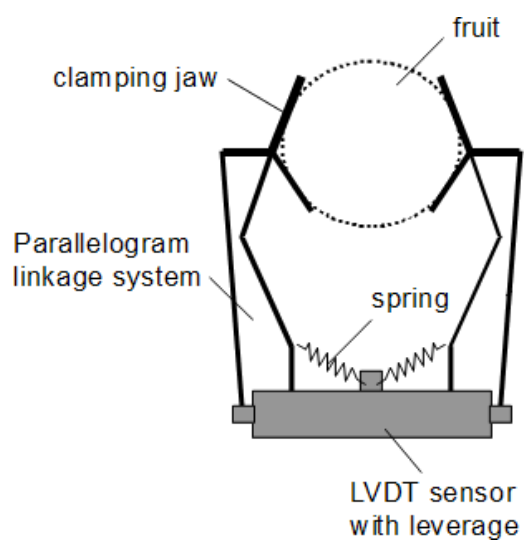

Fig. 1. Schemes of Fruit's Growth Sensor.

LVDT (Linear Variable Differential Transformer) is an electromechanical device used to convert mechanical motion or vibrations, into a variable electrical current, voltage or electric signals, and the reverse. A linear transducer provides voltage output quantity, related to the parameters being measured, for example, force, for simple signal conditioning. LVDT sensor devices are sensitive to electromagnetic interference (no interference from mobile phones and other equipment therefore requires shielding).

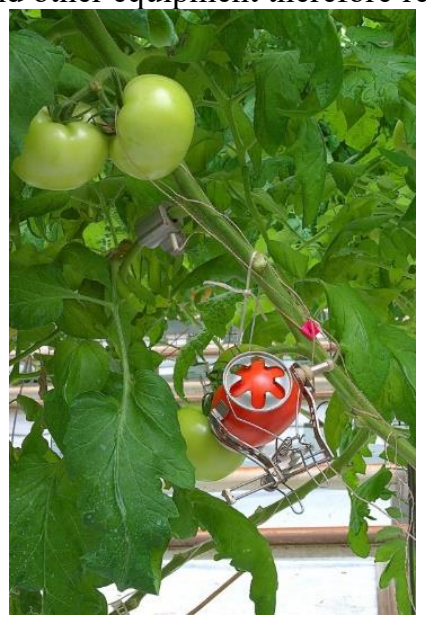

Fig. 2. Fruit's Growth Sensors on tomato plants 
The sensors transmit digital signals to an electronic signal processing unit. The most important task of primary signal processing is noise and interference suppression. In addition, the primary processing solves the problem of signal detection and its quantitative assessment (amplitude, frequency, phase). So the second element of the phytomonitor is an electronic unit for processing signals from sensors for feeding them to a computer, in which special software ensures their processing.

The Digital Signal Processing complex is a PC with a specialized coprocessor in the form of a board that is connected to the PC backbone and structurally built into its case. And since the secondary processing software is characterized by greater flexibility (as opposed to primary) of the algorithms used, the need to support the exchange with another technical means or dialogue with the operator, it is very expensive. As a result, the price of a standard phytomonitor with a set of sensors is 25 thousand euros. Not every greenhouse complex or farmer in the post-Soviet space can afford to purchase a phytomonitor.

\section{Materials and methods}

The measurements were carried out on a phytomonitor in the winter greenhouses of the "Kombinat Teplichny" Corporation (Kiev region, village named "Kalinovka"). The substrate was "Grodan" mineral wool with drip irrigation. Density -2.5 plants $/ \mathrm{m}^{2}$. Variety Raisa F1. Bumblebee evidence was established for pollination of tomato flowers. All sensors for studying environmental factors and plant life processes were installed on a model plant, according to the guidelines of Ilnitsky O. [1]. Receiving information from sensors can be done at intervals of 1-60 minutes. In our research, we chose measurements every 60 minutes. The parameters characterizing various processes of plant life, in particular, the features of their water regime, were measured synchronously with environmental factors and the growth of plant fruits. The measurement of the growth of the fruit was started when its size was $2.7 \mathrm{~cm}$ by selecting one fruit in the raceme. After fruit's maturation, the fruit's growth sensor was re-weighed onto another fruit.

\section{Results}

At the initial stage of growth, the daily increase in fruit's diameter was the highest at 2.5 mm per day (Fig. 3).

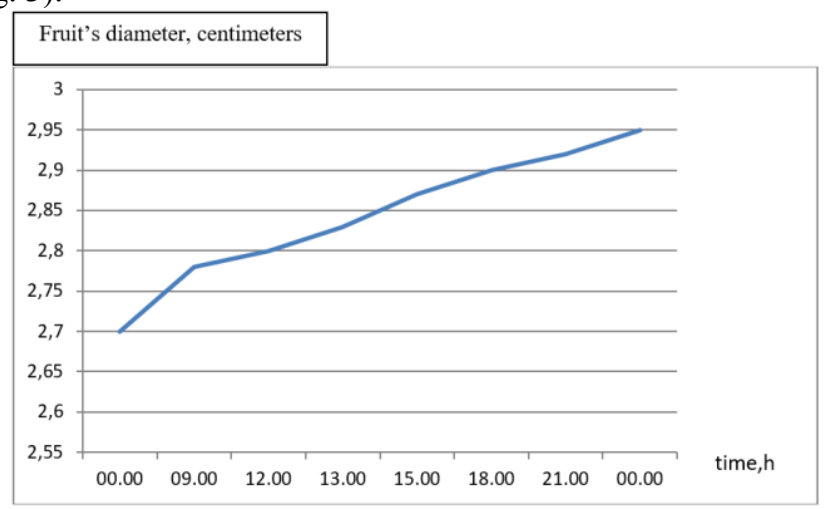

Fig. 3. Tomatoes fruit diameter evolution $(\mathrm{mm})$ on the first days

Especially noteworthy is the time from 0 to 9 o'clock, when the increase is especially intense. As you know, gradual growth of the fruit is considered normal, while any slowdown and even more suspension of growth is considered a physiological disorder and 
is called "depressive trend" in the graphic image. Moreover, in the phytomonitor, fruit's growth indicators are shown primarily in the form of a graph, which is too difficult and clever for low-skilled agronomists.

Then the growth rate increases even more - up to $6 \mathrm{~mm}$ per day, but I must say at this time deviations from normal growth begin, which are called "depressive trend" [3]. This is a slight slowdown in growth during the daytime. This is easily explained by the intense heat at this time, which is confirmed by an increase in leaf and air temperature $\left(31-33^{\circ} \mathrm{C}\right)$, even when the transoms of the ventilation system are fully opened. At the same time, a particularly significant increase occurs in the evening and at night (Fig 4). This is confirmed by the indicator of xylem sap flow. In the morning hours, a gradual increase in speed begins, and it reaches its maximum value at about 7.00-8.00 hours (the first maximum). Then the xylem sap flow rate index decreases up to 19.00-20.00 hours. During these hours, an increase in the xylem flow velocity (second maximum) is observed again, which lasts until 22.00 p.m. - the time of the end of daylight hours.

It should be borne in mind that the temperature of the leaves is an endogenous characteristic of plants, which is influenced not only by changes in the environment, but also by the internal processes of plant's life [2]. During the period from 11.00 to 16.00 , the leaf temperature was higher than the air temperature by $3-6^{\circ} \mathrm{C}$, and sometimes even higher. In these conditions, it is possible to recommend shading the greenhouses during the heat and periodic short-term refreshing sprinkling.

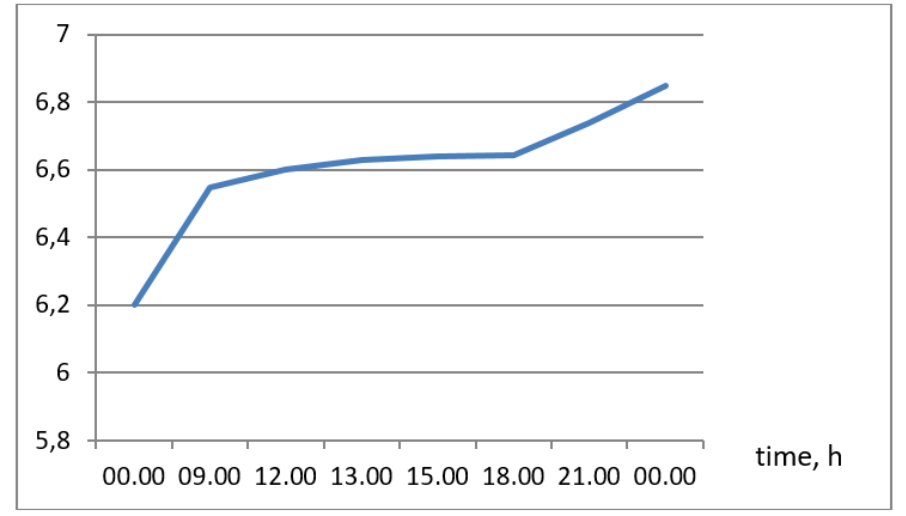

Fig. 4. Dynamics of tomato fruit growth at the next stage.

The greatest fruit's growth occurs from 10 to 20 days, after which the growth curve slows down and then stops altogether (Fig. 5), starting from the moment of milk ripeness.



Fig. 5. Tomatoes fruit diameterldays in dynamics 
Then ripening begins, and the fruit gradually acquires the color typical of the variety. From this moment, the fruit's growth sensor becomes practically unnecessary, and it can be outweighed on another fruits. A similar schedule was observed in all cases, regardless of the period of the year. Some fruits of the same cultivar grew somewhat larger, especially when the fruits were rationed in the cluster. At the same time, not only the size of the fruit increases, but also the growth rate, albeit to an insignificant extent. So, when rationing the first 5 clusters, in which 4 fruits are left, the growth rate of the fruits increases, compared to the following clusters (on which 5 fruits are left). This allows us to conclude about the influence of the number of fruits in the hand and the rationing of the clusters on the growth rate of fruits within one hand. In addition, it was noted that fruits in one cluster ripen unevenly (Fig. 6). In the "Raisa F1" variety, the uniformity of ripening increases as the fruits in one cluster decrease.

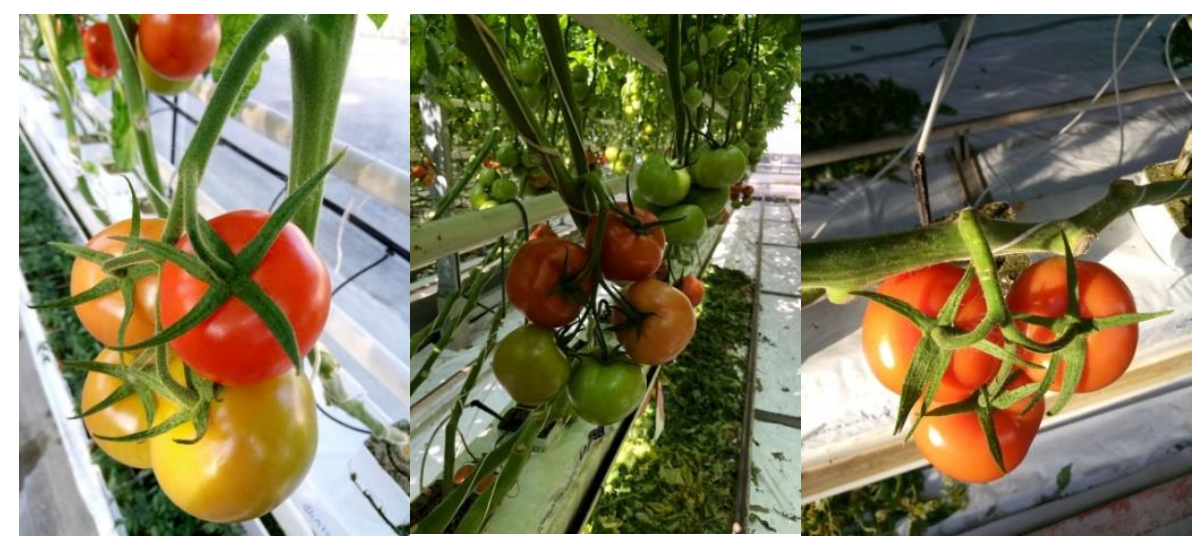

Fig. 6. Clusters of tomato with 4,5 and 3 fruits

For example, if 3 fruits are left on the clusters, they turn red almost evenly. With four fruits on one hand, one of the fruits is characterized by a greater degree of redness compared to the rest, and with 5 - 2 of them are the most reddened, one is still green, one is in brown ripeness, and one is pale red.

\section{Conclusions}

After hanging the growth sensor on fruit with size $2.7 \mathrm{~cm}, 40-42$ days pass until removable ripeness. Moreover, the greatest increase in fruits occurs in the morning, evening and night. During the day, the growth rate decreases, which can be seen from the depressive trend of the growth curve. This is explained in the summer by the presence of intense heat in greenhouses, which is confirmed by an increase in leaf temperature - it is $3-4^{\circ} \mathrm{C}$ higher than the temperature in the greenhouse. Therefore, it is possible to recommend curtain systems and evaporative cooling to prevent the negative influence of high temperatures on fruit growth. The measurements also revealed the influence of the number of fruits in the hand on the rate of their growth and the uniformity of redness. But still, from the point of view of yield, it is not recommended to reduce the number of fruits in a cluster, except for the first 5. The optimal number of fruits per bunch for the studied variety for all subsequent ones is 5 . 


\section{References}

1. O.A. Ilnitskiy, V.A. Ushkarenko, M.I. Fedorchuk, S.S. Radchenko, S.V. Bondarchuk, Methodology and instrumental base of phytomonitoring (Kherson State Agrarian University, 2012).

2. V.A. Odintsova, Scientific Works SKFNTSSVV, 13, 55 (2017).

3. A.V. Tashchilina, Scientific j. of the Russian Research Institute of Melioration Problems, 1(17), 41 (2015).

4. D.S. Intrigliolo, J.R. Castel, Agricultural Water Manage, 83, 173 (2006).

5. Y. Ton, Acta Horticulturae, 562, 257 (2001).

6. U. Schmidt, Acta Horticulture, (2005).

7. S. Mehta, T. F. Burks, W. E. Dixon, Computers and Electronics in Agriculture, 63(1), 28 (2008).

8. I. Korobiichuk, V. Lysenko, V. Reshetiuk, T. Lendiel, M. Kamiński, Int. Conf. on Systems, Control and Information Technologies (Springer International Publishing, 2016). 